\title{
Recurrent Inflammatory Breast Carcinoma
}

National Cancer Institute

\section{Source}

National Cancer Institute. Recurrent Inflammatory Breast Carcinoma. NCI Thesaurus.

Code C8607.

The reemergence of inflammatory carcinoma of the breast after a period of remission 